\title{
Study of the social impact of investment activities of foreign companies on the development of society: a review and analysis
}

\author{
Dinara Rakhmatullayeva ${ }^{1}$, Aiman Khajiyeva ${ }^{2}$, Tolkyn Kakizhanova ${ }^{1}$, and Shalkar \\ Boluspayev $^{1}$
}

${ }^{1}$ Al-Farabi Kazakh National University, 050040 Al-Farabi Avenue 71, Kazakhstan

${ }^{2}$ KazMUCE, Department of MELH, 050040 Manas street 34, Kazakhstan

\begin{abstract}
In this study, based on an analysis of foreign experience, the authors systematized the main tools for assessing the social impact of investments, including foreign direct investment (FDI), on the development of the economy and society. The authors made an attempt to generalize and explore the essence and content of each approach and recommend them for use in Kazakhstan's practice. This is important not only for improving the investment policy in the field of attracting and regulating the activities of direct investors in Kazakhstan, but also for increasing their social responsibility to the country's society.
\end{abstract}

\section{Introduction}

It is well known that foreign direct investment (FDI) brings new knowledge, technologies, and methods of organizing business processes that can significantly accelerate economic growth, and qualitatively change industrial and human capital. FDI is able to provide a significant strengthening of the position of countries that accept capital in the global market competition, allowing them to reinforce their comparative advantages with the results obtained from the use of R\&D and new technologies during the implementation of projects carried out in close cooperation with foreign investors.

In international practice, certain methods, concepts and tools have been developed for assessing the social impact of investments in general, including the impact of FDI on the development of society. For example, methods for assessing the social responsibility of companies make it possible to inform representatives of interested parties about their social development, their contribution to the development of society and their impact on the environment. A review of foreign studies provided the authors with the opportunity to consider a wide range of tools for assessing social impact in the form of concepts, methods, principles, ratings, reports and indexes. The authors examine the most acceptable tools of social assessment for their use in Kazakhstan's practice. 


\section{Methods}

In the study, the authors relied on general scientific methods, such as the logical method, induction and deduction, analysis and synthesis, system analysis, functional analysis, factor analysis.

Based on the application of general scientific methods, the authors were able to identify the main principles, classify the factors, identify the criteria and indicate the significance of each of them, explore the essence and determine the possibilities of their recommendations for domestic researchers.

\section{Discussion}

One of the main methods in foreign practice of assessing the social impact of any processes is the Social Impact Assessment (SIA). In general terms, SIA monitors, analyzes and regulates the social consequences of development. The main goal of this technique is to achieve a more stable and equitable biophysical human environment [1]. As the analysis showed, the main tools for assessing the social effect according to the SIA are the following (Fig. 1):

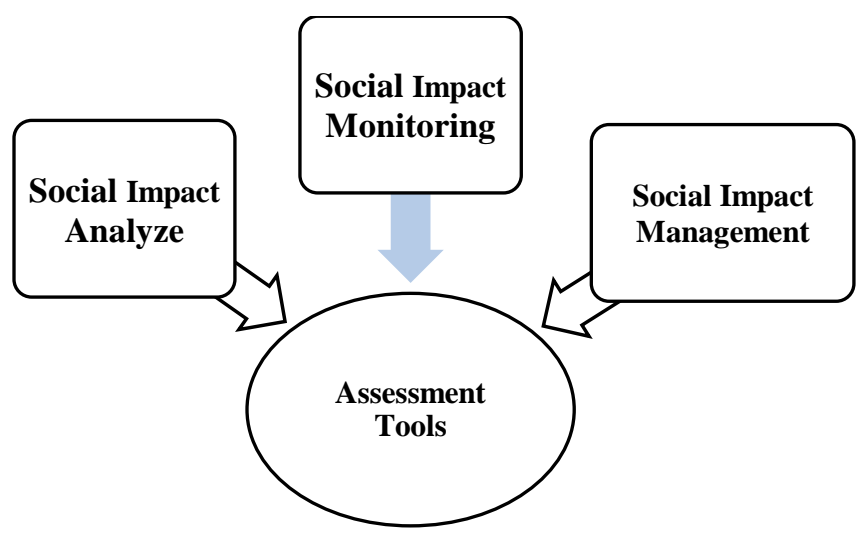

Fig. 1. Assessment tools of social effect by SIA

The SIA methodology is the process of assessing the social consequences of planned events or events and developing a strategy for continuous monitoring and management of these impacts. According to the SIA, the social impact assessment includes three interrelated processes: analysis, monitoring and management of the expected and unintended social consequences, both positive and negative, planned measures (policies, programs, plans, projects) and any social change the process caused by these activities [1].

One of the leading experts in the world in the field of SIA is FrankVanclay, who in his study (2003) claims that the SIA includes an assessment of all impacts on a person and on his lifestyle (with his socio-cultural, economic and biophysical environment) in ways he interacts with other people and society [2]. Thus, the SIA covers a wide range of specialized areas involved in the assessment: aesthetic impact (landscape analysis); the impact of archaeological and cultural heritage (both material and spiritual); community impact; cultural 
implications; demographic implications; development impact; economic and financial implications; gender implications; health and mental health effects; impact on indigenous rights; infrastructural consequences, institutional consequences; the consequences of recreation and tourism; political consequences (human rights, democratization of governance, etc.); consequences of poverty; psychological consequences; access to resources and ownership of resources); impact on social and human capital and other impacts on society [2].

As the analysis of the social impact methodology showed, regardless of what was the source of the social impact (in our case, these are investments made by direct investors in the economy of Kazakhstan), the international practice of assessing its effects recommends relying on the above principles and assessment tools.

This recommended standard for assessing social impact around the world was the basis for assessing the social consequences of the activities of all participants in the international market. We are talking about the concept of Corporate Social Responsibility (CSR) of the leading companies in the world. Therefore, it is permissible to rely on it when assessing the social effect of FDI, too. Corporate social responsibility is understood as the basis of effective business strategies and involves maintaining a balance of interests and building good faith relationships with all interested parties. This concept covers a wide range of business activities in the economic, social and environmental fields [3]. The fundamental works in CSR research are the work of such foreign scientists as Friedman [4], Bowen [5], Carroll [6], Davis [7], Sethi [8], in which the concept, essence and content of social responsibility were specified.

Today, for serious business, and not just for large ones, it becomes obvious that securing a strong position in the national and global economy is achieved on the basis of responsible entrepreneurship by increasing its efficiency and competitiveness. Its necessary conditions include increasing openness and building balanced relationships with all those groups that the business directly affects, and which, in turn, also influence or depend on the success of the business. This is one of the fundamental approaches to understanding CSR, i.e. responsibility to society. This approach is used today by many companies that are moving towards increasing openness and transparency and disclosing their strategy and results in non-financial reports, which are becoming an important element of a responsible business culture. This responsibility implies the need to report to the company for the economic, environmental, and social impact it has as a result of business activity.

Are the processes of development of competition, investment attractiveness of companies and non-financial reporting related? According to many experts and top managers of companies implementing activities on the principles of CSR, the investment attractiveness of companies and the presentation of non-financial reports are two inextricable and interrelated parameters of success. Of course, the transparency of activities provided by the presentation of non-financial statements to the public has a direct and positive impact on the image and reputation of the company, and thereby increase the investment rating and attractiveness of the company in world markets. In other words, such companies are more likely to attract foreign investment than those whose activities are "opaque" to society.

The main topics that find the same and detailed disclosure in the reports include:

$>$ improving the quality of life of the local population: supporting infrastructure of public importance, supporting education and health systems;

$>$ interaction with non-profit organizations (NPOs);

$>$ programs and projects addressed to residents and NPOs: the range of programs is wide, from education to the environment.

In Kazakhstan, a significant role in the development of the principles of social responsibility and the implementation of social reports belongs to the KazEnergy Association, which for the first time in the history of the development of the national 
economy published the concept of CSR in the republic in 2014. In addition, in the field of subsoil use of the republic, companies are developing special development programs that include certain aspects of the social reporting of these companies: in relation to the training and retraining of company specialists, raising their qualifications and knowledge, increasing local content in personnel, in goods and services, and expenses for raising the level of education of workers and residents of the regions in which these companies operate [9].

The investment activity of many companies directly depends on the valuation of wellknown appraisal companies, for example, Standard \& Poors, which assign corporate governance ratings to a company. They are developed as guidelines for investment activity and take into account the assessment of social and environmental reporting and much more in the activities of companies. In this regard, the quantitative measurement of the social contribution of the company is of great interest, which includes:

1) Assessment of the impact of business on the social environment through the preparation of a "social report" in the balance sheet form, which allows you to take into account the social benefits and costs of the company;

2) The use of "social indicators" (assessment of working conditions, health, environment, transport, etc.);

3) The ranking of companies in accordance with their social activities according to criteria such as "law-abiding", "environmental impact", "availability of social programs", etc.;

4) Methods of managing social programs to evaluate the relevant costs, their effectiveness, "social income" on investment.

European practice is based on the social assessment standards of the London Benchmarking Group (1994), the purpose of which is to establish standards for accounting, assessment and reporting on social inclusion of British companies [10]. The model uses a number of concepts: "charity", "contribution to the local community", "commercial initiative", "main types of business activity". With their help, an assessment is made of the costs of the company, its tangible and intangible resources, including working hours of employees, for direct social activities.

American practice is based on the Global Philanthropy Index, which is used by more than 350 American and Canadian firms and is based on the evaluation of the company's activities by various groups of stakeholders (maximum value is 5 , the average value for the USA and Canada is 3.8) [10 ]. In addition to the digital value of the index, the company receives the aggregated value of the social responsibility index of all companies that are currently participating in the rating and the aggregated value of the target sample (by industry, region, size, etc.).

In addition to the above methods for assessing social impact in foreign practice, the Social Return on Investment Concept SROI is also used. This concept has some relevance to other theoretical and practical approaches to evaluating non-economic results, such as the Double Bottom Line, the Blended Value, and the Triple Bottom Line TBL, 3BL, or 3P People, Planet, Profit) [11].

SROI aims to develop a clear methodology for the study, measurement and declaration of social, political, environmental and other non-economic results that are created by projects and organizations. The analysis of social efficiency is based on cost-benefit analysis and social audit aimed at identifying social value (social value, sometimes translated in the scientific literature as social value) created in the project by finding material, financial and non-financial equivalents for social results. SROI analysis measures the value of created goods and the costs of creating these goods.

Formally, the social efficiency of investments is the ratio of the net present value of goods to the net present value of investments. The essence of the SROI analysis is that one or even several indicators, no matter how valuable they are, cannot show the social results of the project, since these results are quite complex in nature. The analysis of the social efficiency 
of investments suggests the possibility to do without quantitative indicators at all, since one of the goals of this methodology is to create the necessary common information space that allows discussing socially significant results with various stakeholders of a social project.

SROI was originally created by experts from the Roberts Enterprise Development Fund (REDF), a charity research foundation based in San Francisco [11]. Since then, the concept has gained wide popularity and distribution. The concept was further developed by specialists from the New Economics Foundation (NEF), an English research organization, who tried to integrate the SROI concept with existing approaches to social reporting. In 2005, the international community International SROI Network agreed on a common methodology for analyzing social performance and developed guidelines for the application of this analysis.

Many researchers and practitioners in the field of assessing the social effect of investments claim that only certain manifestations of the social effect can be accurately measured, in other cases only qualitative assessments and expert conclusions are possible. In addition, they recommend that when assessing the social effect, it is imperative to take into account macroeconomic and regional manifestations of it, bearing in mind that the social effect achieved at the regional level is an integral part of the macroeconomic effect. The scale of the regional social effect is determined not only by absolute, but also by relative indicators that characterize the impact of the investment project on the socio-economic development of the regions. Thus, the magnitude of the social effect is largely determined by the socioeconomic situation in the region. Thus, the effect of introducing new jobs will depend on their percentage of existing jobs in the region and on the situation on the regional labor market.

At the same time, it should be noted that there are cases when certain manifestations of the social effect of investments are not quantifiable, in this case, qualitative methods are used to evaluate them: "The greater the social achievement, the more difficult it is to give it an integral quantitative assessment. To do this, one would have to summarize many effects, some of which have only qualitative characteristics, while others are measured in disparate systems of units. Obviously, it is advisable to develop preference scales covering the entire set of indicators of public welfare, as well as the use of expert assessment methods" [12]. When qualitative assessments of the social effect are needed, independent experts are involved in the work.

From this point of view, the approach of an Iraqi-American scientist-researcher, a major specialist in the field of decision-making evaluation, Saaty (1980), who developed the Analysis Hierarchy Processes (AHP) [13], based on expert assessments using a rigorous mathematical apparatus, is interesting. According to many scholars, AHP is a very good tool for analyzing complex and often controversial social, political and economic problems. AHP is very widely used in practice in all areas of research, because it is the main key to solving many problems of choosing alternatives using multicriteria analysis and rating with a clear mathematical apparatus.

To increase the effectiveness of decision-making in the face of uncertainty, the use of adequate decision-making methods is important. In particular, in the current conditions of the development of the Kazakhstan's economy, taking into account the rapidly changing global trends in the development of the global economy, the decision on the correct choice of an investment project from those proposed by various investors, including foreign ones, is of particular importance, which involves a comparative analysis of their socio-economic effects for national economy. A reasonable option for finding the right solution for a particular investment project is a comparative analysis of its effectiveness based on expert assessments, while the effectiveness of the expert method increases with the rational management of the work of the involved experts.

In international practice, there are special systems for the preparation of decision-making, which have been widely used, for example, the expert-analytical system Expert Decide, the 
MPRIORITY 1.0 system, and the expert-analytical system Expert Solution 1.0, which are based on the application of AHP algorithms. The presence of a rigorous mathematical apparatus in AHP justifies the methods for solving all potential conflict situations associated with the identification of erroneous judgments of expert evaluations in a pairwise comparison of criteria. The convenience and versatility of this technique is that it is possible to mathematically evaluate expert assessments of factor criteria having a non-numerical nature.

The authors indicated above that in addition to social reports, ratings also exist as a tool for assessing social effect. It should be noted that the use of various ratings as a tool for assessing, analyzing, monitoring and managing any processes is widespread throughout the world and has become increasingly popular in recent years. In addition, they serve as a kind of standard for integrating individual economic or other systems into the global system, etc., and in most cases are also based on qualitative or expert assessments.

Regarding the assessment of FDI, the rating of investment attractiveness of countries based on the Investment Trust Index of the international company is widely known abroad. It is the "A.T. Kearney FDI Confidence Index" (FDICI), which ranks countries according to the impact of political, economic and regulatory changes on FDI in the coming years [14]. According to the authors, this index is of great importance for assessing the social effect of FDI as an additional tool in the analysis of the investment climate, therefore, the real prerequisites for the emergence of direct and indirect effects of FDI in Kazakhstan. Large index values indicate high attractiveness for FDI. Since its creation in 1998, the 10 most attractive places in the Rating have consistently received $50 \%$ or more of the global FDI inflow, about a year after the survey [14].

Regarding the social indices known to the public and used in international practice, the authors would like to draw attention to the Quality of Life Russian Regions Ranking [15]. These index is compiled on the basis of a statistical analysis of 61 indicators, which are combined in ten groups that reflect key aspects of the quality of life of the population of a particular region.

At the end of the review, the authors considered the Social Progress Index (SPI), which measures the achievements of countries in terms of social welfare and social progress [16]. This index is a development of American researchers, according to whom the development of the economy is not a sufficient condition for social progress. The index is not based on indicators of economic development of countries; it is used only to assess social development in a country based on 50 indicators.

\section{Results}

Having carried out a deep and holistic analysis of existing methods and approaches to assessing the social impact of companies on the development and vital functions of society in foreign practice, the authors came to the following conclusions:

Firstly, the authors support the basic views of the principles of international experts in the field of social impact and recommend that they be guided in assessing the social effect in Kazakhstan:

1. To explore the essence of the origin of the social effect, to accurately understand it.

2. Take into account public opinion and actively involve the public in the decision-making process.

3. Separate the concepts of quality of life and standard of living. Focus on the first.

4. Take into account and predict the long-term nature of social effects.

5. The principle of justice of social effect. The same people should not get the full amount of effects. 
6. All effects are social effects, and people perceive the physical environment in human terms.

Secondly, the authors revealed that social reports are one of the main tools for the social assessment of the performance of foreign and local companies, including investment. A social report is a document officially published by companies and organizations in which they report on all or a number of key aspects of their activities. As a rule, companies analyze social impacts in two blocks of reports:

$>$ Block on human resources management and personnel relations.

$>$ Block devoted to the participation of companies in the life of local communities.

A very important element of the social report is Block 1, which relates to employees and covers key topics of non-financial reports of foreign companies (Fig. 2).

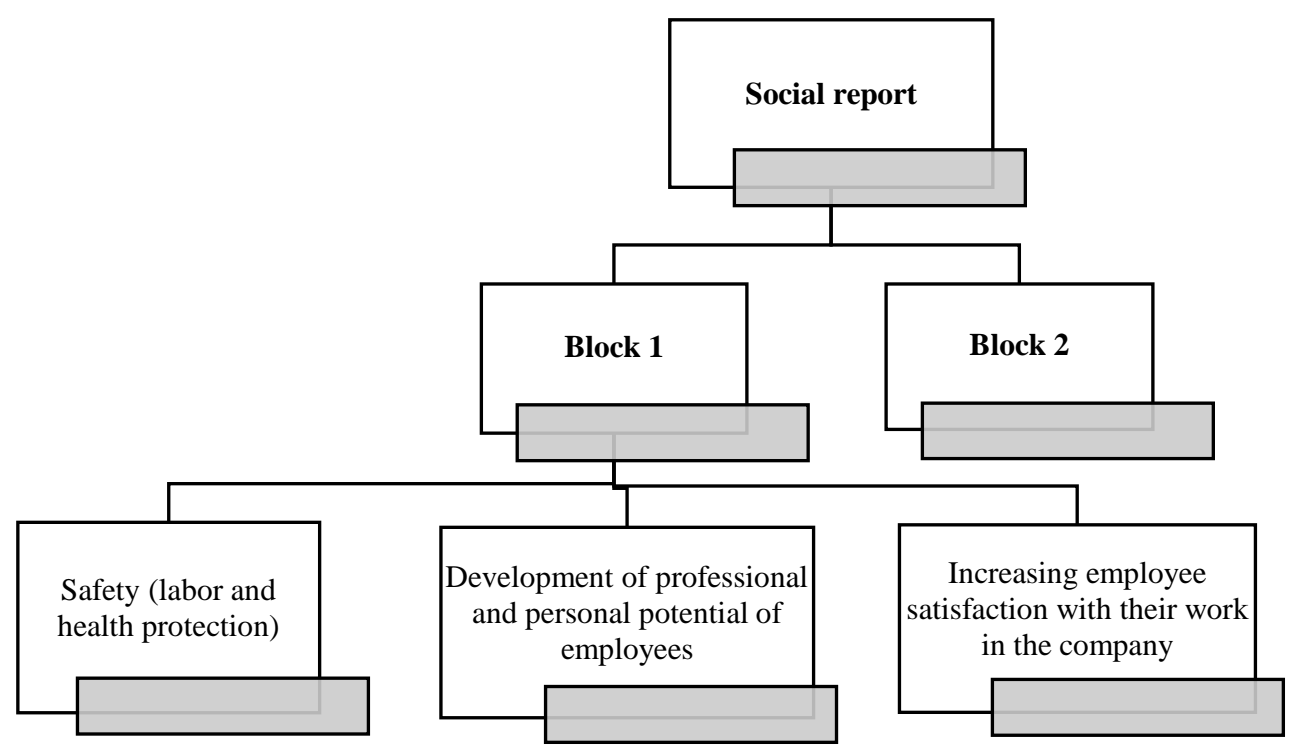

Fig. 2. The structure of the social report

Thirdly, the analysis showed that the social involvement of companies can be assessed through social reports, social ratings, and various social indices, usually based on taking into account the company's influence on the social, environmental and economic situation. Consequently, social reporting includes not only information about the social activities of the company, but also its assessment. Therefore, the authors separately identified the main tools of social assessment in Fig. 3. 


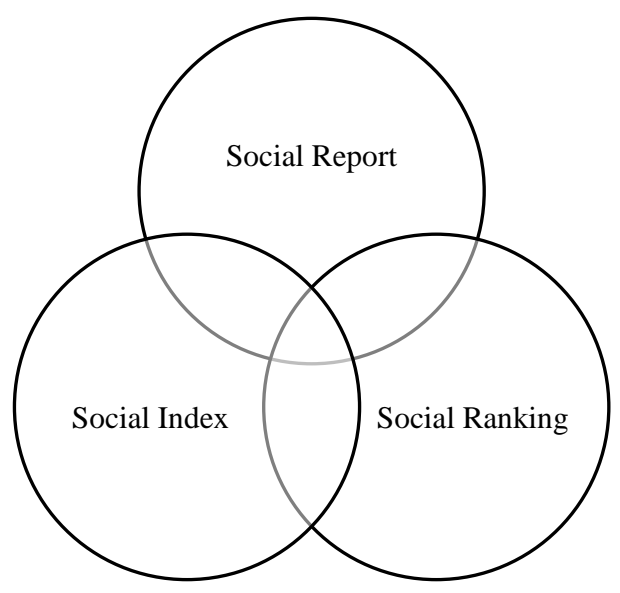

Fig. 3. Tools for assessing the social contribution of companies

Fourth, the authors recommend evaluating particular indicators of the social effect of foreign companies in a given region. These include the following indicators:

1) a change in jobs in the region;

2) an improvement of housing and cultural conditions of workers;

3) a change in the structure of production personnel;

4) a change in the reliability of supplying the population of regions or settlements with individual goods;

5) a changes in the level of health of workers and the population;

6) a saving of free time of the population.

The above indicators attract attention by the fact that, firstly, they are important indicators of the level and quality of life of the population, and secondly, if investment projects implemented by foreign and local companies take into account the social results of their activities, then According to the authors, another tool to influence the improvement of the values of these indicators.

Fifth, as the authors of the study found out, the concept and definition of other, noncommercial, types of effects from investment activity is normal for foreign practice, and for domestic practice this fact has not been studied enough. Unfortunately, Kazakhstan doesn't have a holistic official document regulating the sphere of social consequences of companies. The legislation provides only definitions, but does not provide tools for influencing the consequences of business (responsibility) in the country. The concept of social responsibility, reflected in the Entrepreneurial Code of the country (2016), isn't fully implemented, as is the case in foreign practice. Only national export-oriented companies are participants in the concept of CRS, other local companies do not fully realize their social responsibility to society.

As the author's analysis showed, when it comes to measuring these effects, in particular social ones, one immediately encounters many difficulties and difficulties in determining methods, methods of measuring and evaluating them. In fact, as many researchers admit, the social effects of investments are difficult to measure in practice, in contrast to economic effects. In general, the assessment of social effectiveness is very difficult, so the expert method is most often used for it.

Sixth, a study of the basic principles of SROI analysis allowed the authors to recommend the following of them for use in Kazakhstan:

1. The identification of stakeholders (stakeholders). The entire analysis is based on the identification of specific people, social groups and layers that are affected by the project. 
Also, the methodology involves not only their identification, but also involvement in the processes of creating results and information exchange, which are based on the use of social reporting.

2. Implementation and application of an impact map, which allows you to clearly define how socio-political results and changes are created. It describes the "technology" of how a project or organization impacts change and creates public goods.

3. Focus on the most important elements. SROI analysis is aimed at obtaining better information on socio-political results, and not at obtaining the greatest amount of information. The importance check is aimed at identifying the priorities of project participants or organizations and their reflection in the results of the analysis.

4. Identification of results that would have arisen without a project. The procedure for analyzing the social effectiveness of investments especially carefully examines those benefits that would have appeared without the implementation of the project (these are the so-called "deadweights"). These benefits are identified by comparing situations with and without a project.

Seventh, on the basis of all the studied and analyzed methods and approaches to assessing the social consequences of companies in the world, the authors determined their algorithm for assessing the social effect of FDI in the regions of Kazakhstan, which should include the following five stages:

Stage 1. Determining the ratio of possible effects at the macro and regional levels; identification of regions most affected by FDI.

Stage 2. Analysis of the current state of socio-economic development in the respective regions and forecast of their development trends without taking into account the influence of FDI.

Stage 3. Performing a quantitative and / or qualitative assessment of the types of social effect, comparison with the initial and forecasted regional indicators, and if the scale of the types of effect is significant, then with the general indicators of the country.

Stage 4. Comparison of the positive and negative effects manifested at the macro and regional levels, the derivation of an integrated assessment of the social effect of FDI, the conclusion on the degree of social effectiveness of the investment project.

Stage 5. Comparison of the social and economic efficiency of the project, development of measures to neutralize negative social effects.

The presented scheme for assessing the social effect of investments is universal and applicable to any investment projects, regardless of the source of investment, therefore, the authors are allowed to recommend it for assessing the social effect of FDI, too.

Eighth, the author's study of social development indices in the world showed that they include over 50 indicators that evaluate the country's social development in three aspects:

1. Basic human needs (food, access to basic medical care, housing, access to water, electricity and sanitary services, level of personal safety).

2. Fundamentals of human well-being (access to basic knowledge and literacy, health care, access to information, communication, environmental sustainability).

3. Opportunities for human development (level of personal and civil liberties, ensuring the rights and abilities of a person to make decisions and realize their potential) [16].

\section{Conclusion}

In conclusion, the authors of the study note that, in addition to the above methods and tools for assessing social impact, including the impact of investments and FDI, in foreign practice there are many other approaches and concepts. They differ in the set of tools, in the wording of the assessment method, but common to all approaches is that they are all based on international principles of assessing social impact and have the same goals of identifying, assessing and analyzing social consequences for a person. 
As the analysis of the index of social progress showed, Norway is the world leader in social development, which shows the best results in all key indicators. The top ten also included Denmark, Switzerland, Finland, Sweden, Iceland, New Zealand, Germany, Canada and Japan. Compared with these countries, Kazakhstan (69th in 2019) is still demonstrating relatively low indicators due to poor quality of health care, access to higher education, civil rights and freedoms, as well as environmental problems [16]. At the same time, the republic showed the highest rates in such areas as food, water, sanitary conditions, basic medical care and education.

The study outlined the importance and necessity of taking into account the social impact of the activities of foreign companies on the development of our country and the implementation of methods for this in practice. It is important to understand that the impact of FDI is multifaceted and affects not only the issues of ensuring economic growth in Kazakhstan. FDI can be a catalyst for various changes in the social sphere of development of Kazakhstani society.

\section{References}

1. Guidelines and Principles for Social Impact Assessment, IES, 15, 11-43 (1995)

2. F. Vanclay, EIAR, 22(3), 183-211 (2002)

3. P.L. 91-90, NEPA as amended (P.L. 94-52 and P.L. 94-83) 42 U.S.C. 4321-4347 (1969)

4. M. Friedman, NYTM (1970. Sept. 13)

5. H.R. Bowen, NY: H \& R, 6 (1953)

6. A.B. Carroll B and S, 38 (3), 268-295 (1999)

7. K. Davis, I and V, 629 (1974)

8. S.P. Sethi, HUP, 19 (1975)

9. D. Rakhmatullayeva, T. Kakizhanova, K-S, 3 (69), 66-77 (2014)

10. Social Investment Report, AM, 80 (2004)

11. A. Sitnikov, BSSU, 3 (65), 89-94 (2010)

12. E. Sindyashkina, L and E, 140-147 (2009)

13. T. Saaty, M.: R and C, 278 (1993)

14. FDI CI. URL: //http://www.atkearney.com/

15. QLRRR (2019). URL: https://gtmarket.ru/

16. SPI (2019). URL: http://ranking.kz/ru/ 